\title{
ANALYSIS OF A SAMPLE OF TREACLE AND OF SO-CALLED GOLDEN SYRUP.
}

By Charles George Matrhews, F.I.C., and A. Hyde Parker.

(Read at the Meeting, February 7, 1900.)

Values used in Calculating the two Analyses.

The usual divisor for carbohydrates, 3.86.

Value of a 1 per cent. solution of the sugar observed in a 200-millimetre tube :

\begin{tabular}{llllrr} 
& & \multicolumn{3}{c}{$\begin{array}{c}\text { Soleil-Ventzke- } \\
\text { Scheibler Divisions. }\end{array}$} \\
Maltose & $\ldots$ & $\ldots$ & $\ldots$ & $\ldots$ & 8.02 \\
Laurent \\
Degrees. \\
Dextrin & $\ldots$ & $\ldots$ & $\ldots$ & $\ldots$ & 11.56 \\
Gallisin & $\ldots$ & $\ldots$ & $\ldots$ & $\ldots$ & 3.05 \\
Cane sugar & $\ldots$ & $\ldots$ & $\ldots$ & $\ldots$ & 4.85 \\
2.76 \\
3.98 \\
1.05 \\
1.67 \\
1.32
\end{tabular}


Cupric-reducing values :

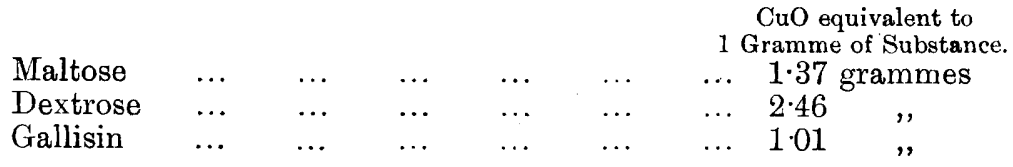

Sample of Treacle (full colour, good flavour, but slightly saline).

A. Calculation of the Gravity due to Ash.-Five grammes of the sample yielded 0.373 gramme of non-sulphated ash, equal to 7.46 per cent. This was shaken up with 100 c.c. of water and the specific gravity of the mixture found to be $1,003.25$; by division $\frac{3 \cdot 25}{0 \cdot 373}=8 \cdot 7$ was obtained as solution factor.

Another 5 grammes yielded 0.4485 gramme of sulphated ash, equal to 8.97 per cent., and this, similarly treated, gave a mixture with a specific gravity of $1,004 \cdot 35$ and a solution factor of $9 \cdot 7$.

The mean of these two percentages of ash was $8 \cdot 21$, and the mean solution factor $9 \cdot 2$.

Determination of the Dry Solids.-The specific gravity of a 10 per cent. solution of the sample was $1,032 \cdot 10$, and the mean specific gravity due to ash in a solution of the same strength was $1,007 \cdot 55$, therefore the specific gravity due to carbohydrates was $1,024 \cdot 55$, which, divided by $3 \cdot 86$, gives $63 \cdot 6$ per cent. of carbohydrates, and this figure added to that of the ash gives 71.81 per cent. total solids.*

B. Determination of the Cane Sugar.-One gramme of pressed yeast was added to 50 c.c. of a 10 per cent. solution of the sample, the mixture kept at a temperature of $52^{\circ} \mathrm{C}$. for five hours, boiled to destroy bi-rotation, made up to bulk, filtered, and examined in a 200 -millimetre tube.

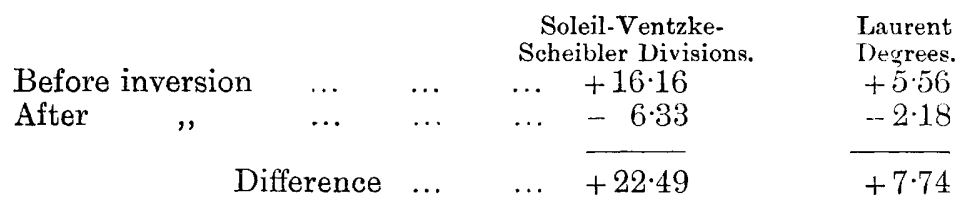

The Soleil-Ventzke-Scheibler divisions, $22.49 \times 10$ and divided by $5 \cdot 02, \dagger$ or the Laurent degrees, $7 \cdot 74$ divided by $0 \cdot 1727$, give $44 \cdot 8$ per cent. of cane sugar.

C. Cupric-reducing Power. - Five grammes of the sample were dissolved in 100 c.c. of water, and the amount of cupric reduction in 2 c.c. estimated gravimetrically by the filter-paper method and weighing as cupric oxide. $\neq$ The weight found 0.0305 grammes $\times 100$ gives 3.05 for a 10 per cent. solution. This figure multiplied by 10 and divided by $2 \cdot 36 \S=12.92$ per cent. reducing sugars.

* Heron (Trans. Fed. Insts. Brewing, 1890, p. 449) regards the sulphated ash as accurately representing the ash without any correction, and he takes the solution factor for the ash as being about double that for the carbohydrates (approximately eight), but seeing that the sulphated ash is perceptibly higher than the plain ash, and the solution factor also higher, the number eight would in our view be sufficiently accurate as applied to the sulphated ash.

$\dagger$ Divisor for 1 per cent. cane sugar solution in 200-millimetre tube when converted into invert sugar.

†ide Morris, Trans. Fed. Insts. Brewing, 1898, p. 164.

$\$$ Mean cupric-reducing power per 1 gramme of invert sugar. (Levulose $=2 \cdot 26$.) 
D. Estimation of the Matter disappearing during Fermentation.-A few grammes of pressed yeast were added to 150 c.c. of a 10 per cent. solution of the sample, and kept at about $18^{\circ} \mathrm{C}$. until fermentation ceased (about seventy-two hours). The solution was then found to have the following constants: Optical activity, 0.0 ; cupricreducing power $\left(\mathrm{K}_{100}\right)$ (10 per cent. solution), 0.65.

The specific gravity lost during fermentation was:

$\begin{array}{llllllll}\text { Original specific gravity } & \ldots & \ldots & \ldots & \ldots & \ldots & 1,032 \cdot 10\end{array}$

Extract gravity after fermentation $\quad \ldots \quad \ldots \quad \ldots \quad 1,010 \cdot 78$

$21 \cdot 32$

This figure, $21 \cdot 32 \times 10 \div 3 \cdot 86=55 \cdot 2$ per cent. sugar which has disappeared during fermentation.

This figure, $55 \cdot 2$, may be compared with that obtained by adding the cane sugar and reducing sugar estimation, viz. :

$$
\begin{array}{lllllllll}
\text { Cane sugar } \ldots & \ldots & \ldots & \ldots & \ldots & \ldots & \ldots & 44 \cdot 0 \\
\text { Reducing sugar } \ldots & \ldots & \ldots & \ldots & \ldots & \ldots & \ldots & 10 \cdot 17 \\
& & & & & & & 54 \cdot 97
\end{array}
$$

The residual cupric-reducing power left after fermentation may be regarded as due to unfermented dextrose and lævulose, and the mean reducing value of these two reducing sugars is 2.36 ( 1 gramme invert sugar $=2.36$ grammes copper oxide). Consequently $0.65 \times 10 \div 2.36=2.75$ per cent. of a mixture of the two sugars, having an optical activity of 0.0 . This calculated out to a mixture of 1.78 per cent. dextrose and 0.97 per cent. lævulose.*

The composition of the fermented matter consisted therefore of :-

$$
\begin{aligned}
& \text { Reducing sugars calculated from original cupric-reducing power } 12.92 \text { per cent. }
\end{aligned}
$$

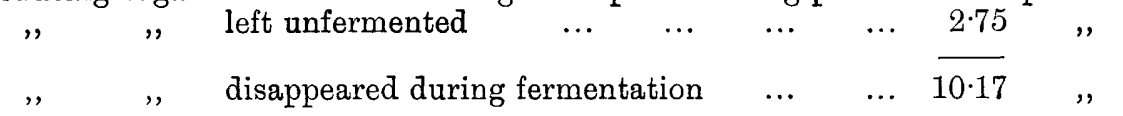

Estimation of the Reducing Sugars removed by Fermentation.-The amount of these is found by subtracting the polarimetric reading corresponding to the cane sugar from that of the original 10 per cent. solution of the sample :

Original solution in 200-millimetre tube ...

Deviation due to cane sugar $(4 \cdot 48 \times 3 \cdot 84)$

$$
\text { Difference } \quad \ldots \quad \ldots \overline{-1.04}
$$

The reducing sugars were found previously to have a copper-reducing value of 2.4 in a 10 per cent. solution, and, since their optical activity was -1.04 , they consisted of a mixture of 4.83 parts lævulose and 5.34 dextrose. These amounts added to the same sugars which were left unfermented equal $5 \cdot 80$ per cent. lævulose and $7 \cdot 12$ per cent. dextrose. (For mode of calculation, see previous footnote.)

* The composition of the mixed sugars is calculated as follows: Let $x=$ the dextrose and $(2 \cdot 75-x)$ $=$ the lævulose, then $x \times 52 \cdot 8+(2 \cdot 75-x) \times-95 \cdot 65=0$, and $x=1 \cdot 78$. 
The complete analysis was as follows :

$$
\begin{aligned}
& \begin{array}{lllllllll}
\text { Cane sugar } & \ldots & \ldots & \ldots & \ldots & \ldots & \ldots & \ldots & 44.80
\end{array} \\
& \begin{array}{llllllllr}
\text { Lane sugar } & \ldots & \ldots & \ldots & \ldots & \ldots & \ldots & \ldots & 4480 \\
\text { Levulose } & \ldots & \ldots & \ldots & \ldots & \ldots & \ldots & \ldots & 5.80
\end{array} \\
& \begin{array}{lllllllll}
\text { Dextrose } & \ldots & \ldots & \ldots & \ldots & \ldots & \ldots & \ldots & 7 \cdot 12
\end{array} \\
& \begin{array}{lllllllllll}
\text { Ash } & \ldots & \ldots & \ldots & \ldots & \ldots & \ldots & \ldots & \ldots & 8.21
\end{array} \\
& \begin{array}{llllll} 
& \ldots \\
\text { Unaccounted for }=\text { inactive matter } & \ldots & \ldots & \ldots & \ldots & 5.87
\end{array} \\
& \text { Difference }=\text { moisture } \quad \ldots \quad \ldots \quad \begin{array}{r}
\frac{71 \cdot 80}{28 \cdot 20} \\
\hline 100 \cdot 00
\end{array}
\end{aligned}
$$

Had the results been calculated in the old way, viz., by dividing the weight about 1,000 of the 10 per cent. solution by $3 \cdot 86$, we should have the following :

$$
\text { Specific gravity } 1,032 \cdot 1 \text { and } \frac{32 \cdot 1}{3 \cdot 86} \times 10=83 \cdot 16 \text { per cent. ; }
$$

83.16 would then have been formerly taken as the true solids, and the difference as moisture, and the above analysis (excluding any question of newer methods and values used in calculating the cane sugar, dextrose, and lævulose) would have become :

\section{Summary.}

\begin{tabular}{llllllllr} 
Cane sugar & $\ldots$ & $\ldots$ & $\ldots$ & $\ldots$ & $\ldots$ & $\ldots$ & $\ldots$ & $44 \cdot 80$ \\
Lævulose & $\ldots$ & $\ldots$ & $\ldots$ & $\ldots$ & $\ldots$ & $\ldots$ & $\ldots$ & $5 \cdot 80$ \\
Dextrose & $\ldots$ & $\ldots$ & $\ldots$ & $\ldots$ & $\ldots$ & $\ldots$ & $\ldots$ & $7 \cdot 12$ \\
Ash $\ldots$ & $\ldots$ & $\ldots$ & $\ldots$ & $\ldots$ & $\ldots$ & $\ldots$ & $\ldots$ & $8 \cdot 21$ \\
Inactive matter & $\ldots$ & $\ldots$ & $\ldots$ & $\ldots$ & $\ldots$ & $\ldots$ & $17 \cdot 23$ \\
Difference=moisture & $\ldots$ & $\ldots$ & $\ldots$ & $\ldots$ & $\ldots$ & $\ldots$ & $16 \cdot 84$ \\
\hline
\end{tabular}

Sample of so-called Golden Syrup (full golden colour, pleasant flavour).

A. Five grammes of the sample yielded 0.067 grammes of sulphated ash $=1.34$ per cent.

Specific gravity corresponding to ash in 10 per cent. solution $0 \cdot 134 \times 8=1,001 \cdot 07$.

Specific gravity of 10 per cent. solution of sample $\quad \ldots \quad \ldots \quad 1,030 \cdot 40$

Correction for ash

$$
\begin{array}{rrrrrr}
\cdots & \ldots & \ldots & \ldots & \ldots & 1.07 \\
1,029 \cdot 33
\end{array}
$$

$29 \cdot 33 \div 3 \cdot 86 \times 10=$ Carbohydrates per cent

$$
\text { Ash }
$$$$
\begin{array}{rrrr}
\cdots & \cdots & \cdots & 75 \cdot 92 \\
\cdots & \cdots & \cdots & 1.34
\end{array}
$$

\section{Total solids}

$77 \cdot 26$

B. By inversion with yeast, as in the former case, $11 \cdot 3$ per cent. of cane sugar was found.

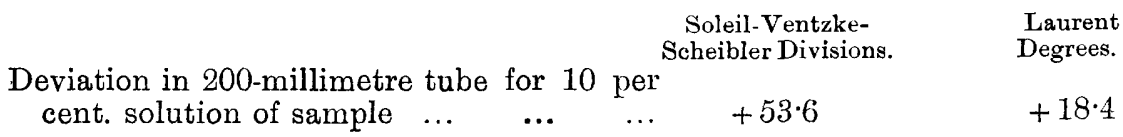


C. Cupric-reducing power of 100 c.c. of 10 per cent. solution, 7.65 grammes $\mathrm{CuO}$.

D. Specific gravity of 10 per cent. solution before fermentation ... $1,030 \cdot 4$ Extract ,

after

... $1,013 \cdot 5$

Loss

,

$16 \cdot 9$

$16.9 \div 3 \cdot 86 \times 10=43 \cdot 70$ per cent. fermented.

33.56 , unfermented.

Deviation in 200-millimetre tube after fer-

$\begin{array}{llllllll}\text { mentation } & \ldots & \ldots & \ldots & \ldots & \ldots & +31 \cdot 2 & +10 \cdot 7\end{array}$

Cupric reduction in 100 c.c. ... $\quad \ldots \quad \ldots \quad \ldots \quad \ldots \quad \ldots .1544$ grammes

E. Determination of combined Dextrin (Amylön-dextrin).--Any maltose existing in combination as malto-dextrin would reveal its presence by an increased reducing power after treatment of the fermented solution with cold-water malt-extract, $*$ and this released maltose would be removed by a subsequent fermentation with yeast. To 100 c.c. of the fermented 10 per cent. solution 10 c.c. of malt-extract were added, and the mixture kept at a temperature of $55^{\circ} \mathrm{C}$. for two hours.

A considerable increase in the cupric-reducing power ensued ( $=18.3$ per cent. of dextrin), but inasmuch as the solution after treatment with malt extract was not susceptible of fermentation to an appreciably further point than the non-treated portion, we do not consider ourselves justified in using the figure so obtained for dextrin.

The same rather curious fact has been noticed in the case of two or three other syrups which had been undoubtedly manufactured from cereals or cereal starch.

This consideration of the failure of the solution treated with malt-extract to ferment further than the untreated solution, also affects the question of the combined maltose, which should be-like the maltose produced from hydrolysed dextrinrendered fermentable by the action of the cold-water malt-extract, and therefore the whole cupric reduction shown by the 10 per cent. solution after plain fermentation is not to be calculated as combined maltose. There is, on the contrary, every reason to believe that it is mainly due to gallisin, and it will be seen that consistent results are to be obtained if this view be adopted.

We assumed the residual cupric-reducing value of 1.46 to be due to gallisin, and $1.46 \times 10 \div 1.01=14.4$ per cent. of gallisin. This amount would cause a deviation in a 200-millimetre tube of $1.44 \times 4.85=6.98$ Soleil-Ventzke-Scheibler divisions, or $1 \cdot 44 \times 1 \cdot 67=2 \cdot 40$ Laurent degrees.

The deviation observed after re-fermenting the fermented solution which had been treated with malt-extract was 22.8 Soleil-Ventzke-Scheibler divisions, or 7.84 Laurent degrees, and this, less the deviation due to gallisin, was $22 \cdot 28-6 \cdot 98=15 \cdot 3$ Soleil-Ventzke-Scheibler, or 5.26 Laurent degrees, and either $(15 \cdot 3 \times 10 \div 11.56)$ or $(5 \cdot 26 \times 10 \div 3 \cdot 98)$ equal $13 \cdot 2$ per cent. of dextrin.

* Made by intimately mixing 100 grammes of finely-ground pale malt with 250 c.c. of water, and allowing the mixture to stand for twelve hours, giving it an occasional stir. The clear filtrate is used (vide Morris and Moritz, "Text-book of Brewing," pp. 477-480). 
The matter remaining after treatment with malt-extract and re-fermentation amounted to 30 per cent., and as $27 \cdot 6$ per cent. was shown to be gallisin and dextrin, $2 \cdot 4$ per cent. was left unaccounted for.

The total matter which had disappeared during the first fermentation was 43.7 per cent., and deducting from this the 11.3 per cent. of cane sugar, 32.4 per cent. of reducing sugars were fermented. These consisted of a mixture of maltose and dextrose, having a cupric-reducing value of $6 \cdot 106$ (original $\mathrm{K}_{100} 7 \cdot 65$-residue $\mathrm{K}_{100}$ 1.544), which equals 1.88 grammes of $\mathrm{CuO}$ to 1 gramme of substance. The deviation in a 200 -millimetre tube equal to this 32.4 per cent. of substance was :--

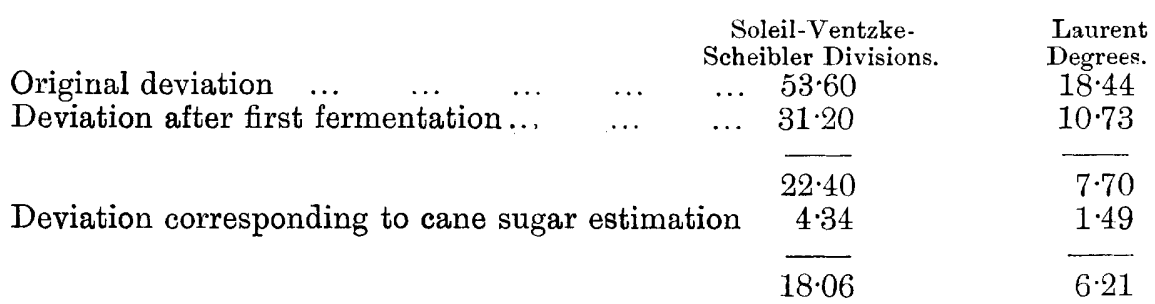

And either $(18.06 \times 10 \div 32 \cdot 4=5 \cdot 57$, divisor Soleil-Ventzke-Scheibler $)$ or $(6 \cdot 21 \times$ $10 \div 32 \cdot 4=1 \cdot 91$, divisor Laurent) equal the deviation in a 200 -millimetre tube due to 1 gramme of substance.

These values correspond to a mixture of 16.84 parts of maltose and 15.56 dextrose.*

Summary.

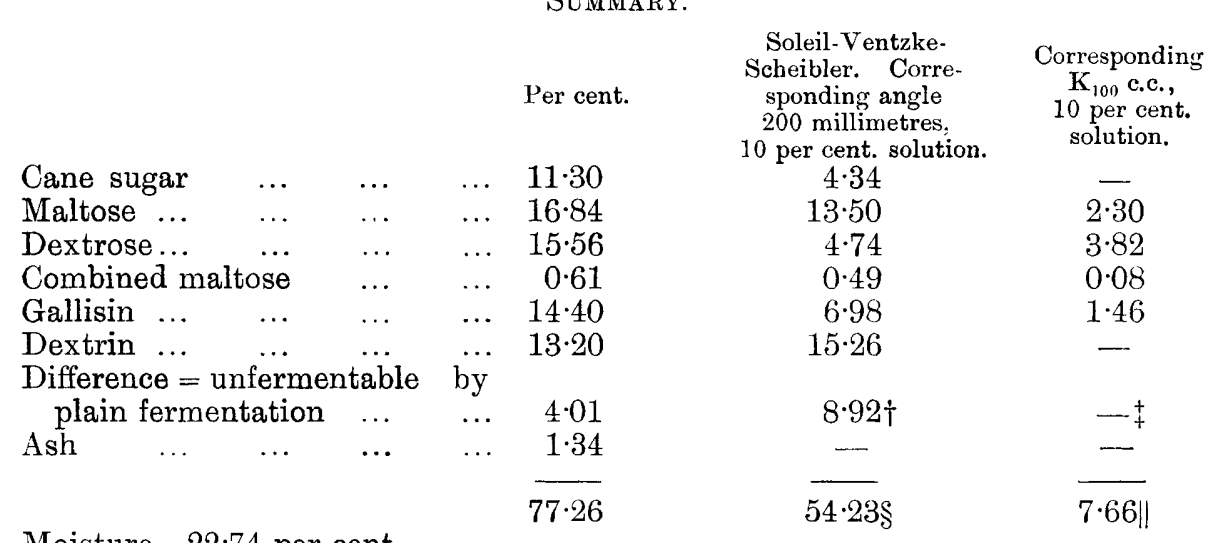

* From the cupric-reducing value :

$$
2 \cdot 46 x+1 \cdot 37(1-x)=1 \cdot 88, \text { and } x=\frac{51}{109} \text { dextrose. }
$$

From the rotation :

$$
3 \cdot 05 x+8 \cdot 02(1-x)=5 \cdot 57, \text { and } x=\frac{245}{497} \text { dextrose. }
$$

+ Angle disappearing on degrading and refermenting.

$\mp \mathrm{K}$ taken account of already as combined maltose.

$\$$ Compare with original angle 200 millimetres. 


\section{Discussion.}

The Chairman (Mr. A. H. Allen) invited discussion, with special reference to the question of refermentation after the addition of malt-extract, and to the authors' assumption that gallisin was a substance of definite composition, possessing a definite reducing power and optical activity.

Dr. Sykes said that in all starch conversions, whether effected by acid or by diastase, undoubtedly certain bodies were present which could not be fermented by yeast alone, but which under the combined influence of yeast and diastase were readily fermentable, a fact utilized by the spirit or vinegar manufacturer, who did not boil his wort, and consequently preserved his diastase intact during the fermentation. In a glucose determination the removal of these bodies was, as mentioned in the paper, secured by fermenting the once fermented solution after the addition of maltextract.

Dr. Dyer said he considered that, in dealing with this subject, a mistake had often been made in treating treacle, or any form of sugar syrup-a mixture of cane sugar and invert sugar-as an entity. Glucose syrup, however, for all practical purposes, could be so treated. Certain figures could be assumed as being safe outside limits to take for commercial glucose syrup, but no figures at all could be taken as representing constants for treacle or golden syrup.* Probably, indeed, some of the mixtures which had to be dealt with were not mixtures of glucose syrup with what would be called golden syrup or treacle, but consisted of commercial glucose syrup with the addition of crude sugar of some kind dissolved in water. In such cases the cane sugar was far higher in proportion to the invert sugar than would be the case in ordinary treacle or inverted syrup made from sugar. With the assistance of Mr. Sydney Steel, and from information kindly furnished to him by other chemical friends with experience in glucose syrup, he had arrived at the conclusion that it was quite safe to assume certain constants for glucose syrup : not exactly average figures, but figures representing the outside limits likely to be met with in the glucose syrup used for these mixtures--figures which would, if anything, give to the mixer the benefit of any doubt. The following were the figures assumed for glucose syrup :

$$
\begin{aligned}
& \text { Specific rotatory power }-[\alpha]_{D} \quad \ldots \quad \ldots \quad \ldots \quad \ldots+113 \cdot 0 \\
& \text { Cupric oxide reducing power ("K value") } \quad \text {.. } \quad 42
\end{aligned}
$$

Where a polarimeter was used, which was graduated, not for angles, but for percentages of sugar, the rotation for "normal weight" dissolved in 100 c.c. of water was +170 divisions. Occasionally samples of glucose syrup were met with having a higher rotation, but such cases were exceptional. From polarization at $20^{\circ} \mathrm{C}$., before and after inversion (by Herzfeld's method), and determination of the copper reducing power, the percentage of glucose syrup was calculated from the following formula, in which $R$ stands for the specific rotatory power $[\alpha]_{D}$, at $20^{\circ} \mathrm{C}$, of the uninverted sample, $\mathrm{S}$ for the + rotation due to the sucrose present, and $\mathrm{K}$ for the copper reducing power :

$$
\text { Percentage of glucose syrup }=\frac{0 \cdot 206 \mathrm{~K}+(\mathrm{R}-\mathrm{S})}{1 \cdot 217} .
$$

* Mr. Jones, in his paper on p. 87 of this number, suggests that, after inversion, sugar syrup may be regarded as an " entity." This materially reduces the liability to error through the assumption of a constant composition, but appears less satisfactory than the mode of calculation described in this paragraph.-B. D. 
If a polarimeter reading percentages were used, and the observation made on "normal weight" of the syrup, $\mathrm{R}$ being the "percentage" reading before inversion and $\mathrm{S}$ the percentage of sucrose, the formula was:

$$
\text { Percentage of glucose syrup }=\frac{0 \cdot 31 \mathrm{~K}+(\mathrm{R}-\mathrm{S})}{1 \cdot 83} \text {. }
$$

The method was substantially that described some time back by Mr. Boseley for the estimation of glucose in marmalade, differing mainly in that the syrup, and not the " solids" dissolved in it, was treated as the direct basis of calculation. Mr. Chapman, after making a number of analyses of syrups more or less on the lines of those detailed in the paper of Messrs. Matthews and Hyde Parker, had also applied to his results this simple mode of calculation, and an interesting comparison was thus afforded between this method and the more elaborate and more scientific determinations which took into account the percentages of the different individual carbohydrates present.

Mr. Chapman said that, whilst the rotation and copper oxide reducing power obtained, after fermentation were assumed by the authors to be due to unfermented dextrose and lævulose, modern methods of sugar analysis were to a great extent based on the assumption (which was universally believed to be justifiable) that dextrose and lævulose were, under proper conditions, entirely fermentable, and he ventured to think that the numbers referred to should rather be regarded as due to certain unfermentable bodies allied to the carbohydrates, which were well known to exist in raw sugars and in invert sugar, and to be possessed of very little optical activity, but of considerable cupric oxide reducing power. In some analyses of raw sugar recently published by Mr. Glendenning, unfermentable residues, which undoubtedly did not consist of carbohydrates, being possessed of very little optical activity, but having a cupric oxide reducing power of about 30, were shown to exist in almost all raw sugars in the proportion of from 1 to 3 per cent. With regard to the question of gallisin, he thought it a pity that definite assumptions should be made in regard to so indefinite a substance. The substance called gallisin had been obtained some years previously by a method which offered practically no guarantee as to its purity, and a body somewhat resembling it had since been obtained from glucoses and other commercial carbohydrate mixtures; but he thought there was insufficient evidence to warrant its being regarded as a body of definite composition. He had, as Dr. Dyer had mentioned, made analyses of a number of samples of adulterated treacle, four of which gave the following results :

\begin{tabular}{|c|c|c|c|c|c|c|}
\hline Cane sugar & $\ldots$ & $\ldots$ & $\begin{array}{l}\text { No. } 1 . \\
20.63\end{array}$ & $\begin{array}{l}\text { No. } 2 \text {. } \\
26 \cdot 10\end{array}$ & $\begin{array}{l}\text { No. } 3 . \\
27.40\end{array}$ & $\begin{array}{l}\text { No. }{ }^{4} . \\
4 \cdot 10\end{array}$ \\
\hline Invert sugar & $\cdots$ & $\ldots$ & $10 \cdot 80$ & $12 \cdot 00$ & $23 \cdot 60$ & - \\
\hline Dextrose & $\cdots$ & $\ldots$ & $6 \cdot 10$ & $22 \cdot 00$ & $11 \cdot 40$ & $31 \cdot 70$ \\
\hline Maltose ... & $\ldots$ & $\ldots$ & $26 \cdot 40$ & $\cdot 40$ & $\ldots$ & $7 \cdot 50$ \\
\hline Dextrin ... & $\ldots$ & $\ldots$ & $12 \cdot 95$ & 8.98 & $2 \cdot 50$ & $34 \cdot 30$ \\
\hline Water ... & $\ldots$ & $\ldots$ & $19 \cdot 08$ & $20 \cdot 50$ & $22 \cdot 69$ & $21 \cdot 30$ \\
\hline Ash $\quad \ldots$ & $\ldots$ & $\ldots$ & $1 \cdot 82$ & $5 \cdot 20$ & $7 \cdot 24$ & $1 \cdot 10$ \\
\hline Undetermined & $\ldots$ & $\ldots$ & $2 \cdot 22$ & $4 \cdot 82$ & $5 \cdot 17$ & - \\
\hline & & & $100 \cdot 00$ & $100 \cdot 00$ & $100 \cdot 00$ & $100 \cdot 00$ \\
\hline Optical acti & vity & 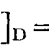 & $+77 \cdot 3^{\circ}$ & $+45 \cdot 2^{\circ}$ & $+24 \cdot 6^{\circ}$ & $+99.01^{\circ}$ \\
\hline
\end{tabular}


From a consideration of their carbohydrate constituents, he had concluded that they contained 52, 32, 13 and 87 per cent. of glucose syrup respectively ; the comparatively simple method of calculation explained by Dr. Dyer gave 56.9, 27.3, 10.5 and 86.4 as the respective percentages of glucose syrup. He was now quite satisfied that the simpler method of dealing with the subject was quite sufficient for the practical purpose of determining the approximate percentage of glucose syrup in these mixtures.

Mr. Boseley said that he had employed the method referred to in his paper on "The Analysis of Marmalade" (ANALYst, xxiii., 123) in the analysis of a very large number of samples of jam, and had found it to work most admirably. In determining the cupric oxide reducing power in a jam, however, it was necessary to remember that in some fruits there was present a substance which was not sugar, but which, apart from the natural invert sugar of the fruit, was capable of reducing Fehling's solution, and the results published in 1898 were probably about 2 per cent. too high owing to the influence of this substance, of the presence of which, in sufficient quantity to affect the results, he was not at the time aware. He had examined a great many samples of glucose syrup, and had not found the rotation to vary largely. The figure he had adopted for " percentage" rotation (cane sugar $=100$ ), viz., 166

$$
\text { (or Sp. R. P. }[\alpha]_{\mathrm{D}}=+110^{\circ} \text { ), }
$$

was an average of between 200 and 300 samples obtained from different sources, the highest result obtained being 173

$$
\text { (or Sp. R. P. }[a]_{D}=+115^{\circ} \text { ). }
$$

Mr. Julian L. Baker said it seemed very unsatisfactory that in the determination of cupric reducing power the method of weighing as cupric oxide should still be indulged in. It was far more accurate, and was now almost universal-at any rate, amongst Continental chemists-to weigh as metallic copper. It made a great difference whether, in speaking of gallisin, the authors meant conversion products, or whether they meant the unfermentable residues of starch conversion. On degrading starch by means of malt-extract in the cold, a substance was obtained which was practically wholly fermentable; whereas, if the operation were conducted at a higher temperature, conversion products were obtained which were not completely fermentable. Some of these unfermentable products had been examined by Mr. Ling and himself, and had been found to consist of bodies having the formula $\mathrm{C}_{12} \mathrm{H}_{22} \mathrm{O}_{11}$. Their composition thus resembled that of maltose, and they were non-crystalline and had a fairly high reducing power. He was at present working, together with Mr. T. H. Pope, upon a series of polysaccharides, which occurred largely in the vegetable kingdom, and among which was probably the body mentioned by Mr. Boseley. They were non-crystalline, and yielded definite sugars on hydrolysis. He had recently isolated one of these bodies from the ivory nut, having the composition $\mathrm{C}_{6} \mathrm{H}_{10} \mathrm{O}_{5}$, which on hydrolysis yielded considerable quantities of mannose, in addition to a lævo-rotatory sugar, probably lævulose, and which, while reducing Fehling's solution, decomposed at high temperatures, a peculiarity not possessed by the other members of the series which he had examined.

Mr. ARchiuts recommended the method of estimating cuprous oxide recently described by Messrs. Caven and Hill before the Nottingham section of the Society of 
Chemical Industry, ${ }^{*}$ in which the precipitate was filtered on an asbestos mat in a Gooch crucible, and transferred, after thorough washing with boiling distilled water, to a flask containing a mixture of dilute sulphuric acid and standard potassium permanganate solution, the excess of permanganate being titrated with oxalic acid or hydrogen peroxide. 